\title{
Fault delineation study using soil-gas method in the Dharamsala area, NW Himalayas, India
}

\author{
Vivek Walia ${ }^{\mathrm{a}, *}$, Sandeep Mahajan ${ }^{\mathrm{b}}$, Arvind Kumar ${ }^{\mathrm{b}}$, Surinder Singh ${ }^{\mathrm{b}}$, Bikramjit Singh Bajwa ${ }^{\mathrm{b}}$, \\ Sunil Dhar ${ }^{\mathrm{c}}$, Tsanyao Frank Yang ${ }^{\mathrm{a}, \mathrm{d}}$ \\ ${ }^{a}$ National Center for Research on Earthquake Engineering, National Applied Research Laboratories, Taipei-106, Taiwan \\ ${ }^{\mathrm{b}}$ Department of Physics, Guru Nanak Dev University, Amritsar, India \\ ${ }^{\mathrm{c}}$ Department of Geology, Govt. College, Dharamsala, Himachal Pradesh, India \\ ${ }^{\mathrm{d}}$ Department of Geosciences, National Taiwan University, Taipei-106, Taiwan
}

\begin{abstract}
Soil-gas activity in the vicinity of neotectonic fault zones within the Dharamsala area in the region of the NW Himalayas, India, has been investigated by determining enhanced concentration values of radon and helium in the soil, using an ionization chamber and an ASM 100 HDS (Alcatel), respectively. A geological map of the area was used for site selection and to locate the predicted courses of faults. Elevated levels of radon and helium in the soil gas were found along a profile of a major fault (MBT-2). Radon shows variation not only due to the tectonic structures but also due to change in lithology. Helium and radon anomalies together show that apart from conspicuous thrust MBT-2, the area under study is cut across by the N-S transverse faults/lineaments.
\end{abstract}

(c) 2008 Elsevier Ltd. All rights reserved.

Keywords: Soil-gas; Fault delineation; Radon; Helium; Dharamsala

\section{Introduction}

Many studies in tectonic areas have shown a possible correlation of soil-gas anomalies with tectonic activity (Ciotoli et al., 1998; Yang et al., 2003; Fu et al., 2005; Walia et al., 2005a, 2006). It has been found that active blind faults that are not exposed at the surface can be detected by soil-gas surveys ( $\mathrm{Fu}$ et al., 2005; Walia et al., 2005a). Radon and helium play predominant roles in fault delineation and earthquake precursory studies (Toutain and Baubron, 1999; Chyi et al., 2005; Fu et al., 2005; Walia et al., 2005a, b, 2006; Yang et al., 2005, 2006) and both are products of uranium/thorium decay series. Radon due to its short half-life displays poor intrinsic mobility, while helium is characterized by its high mobility and low solubility in water. Due to these reasons, helium shows a highly diffusive character with diffusion coefficient $\left(1.68 \mathrm{~cm}^{2} / \mathrm{s}\right)$ about

\footnotetext{
* Corresponding author. Tel.: +88626630 0575; fax: +886266300858. E-mail addresses: vivekwalia@rediffmail.com,walia@ncree.org.tw
} (V. Walia). ten times higher than that of $\mathrm{N}_{2}, \mathrm{O}_{2}$ and $\mathrm{CO}_{2}$. Due to its characteristics and deep origin with respect to radon, helium appears as a powerful pathfinder for crustal discontinuities, faults and fractures (Ciotoli et al., 1998; Font et al., 2007; Fu et al., 2008). Short-term fluctuations of the helium flux have been used as a possible precursor of earthquake activity (Walia et al., 2006). The present study aims at assessing the relationship between soil-gas radon/helium distribution and thrust/neotectonic fault zones in the vicinity of tectonically active area of Dharamsala in the region of NW Himalayas, India.

\section{Experimental procedures}

\subsection{Study area}

Himalayan orogen is a by-product of the continent-tocontinent collision due to the convergent movement of the Indian plate towards the Eurasian plate. A series of major thrust planes, the main central thrust (MCT), the main boundary thrust (MBT) and the main frontal thrust (MFT), have been formed as a result of these processes (Gansser, 1964). 


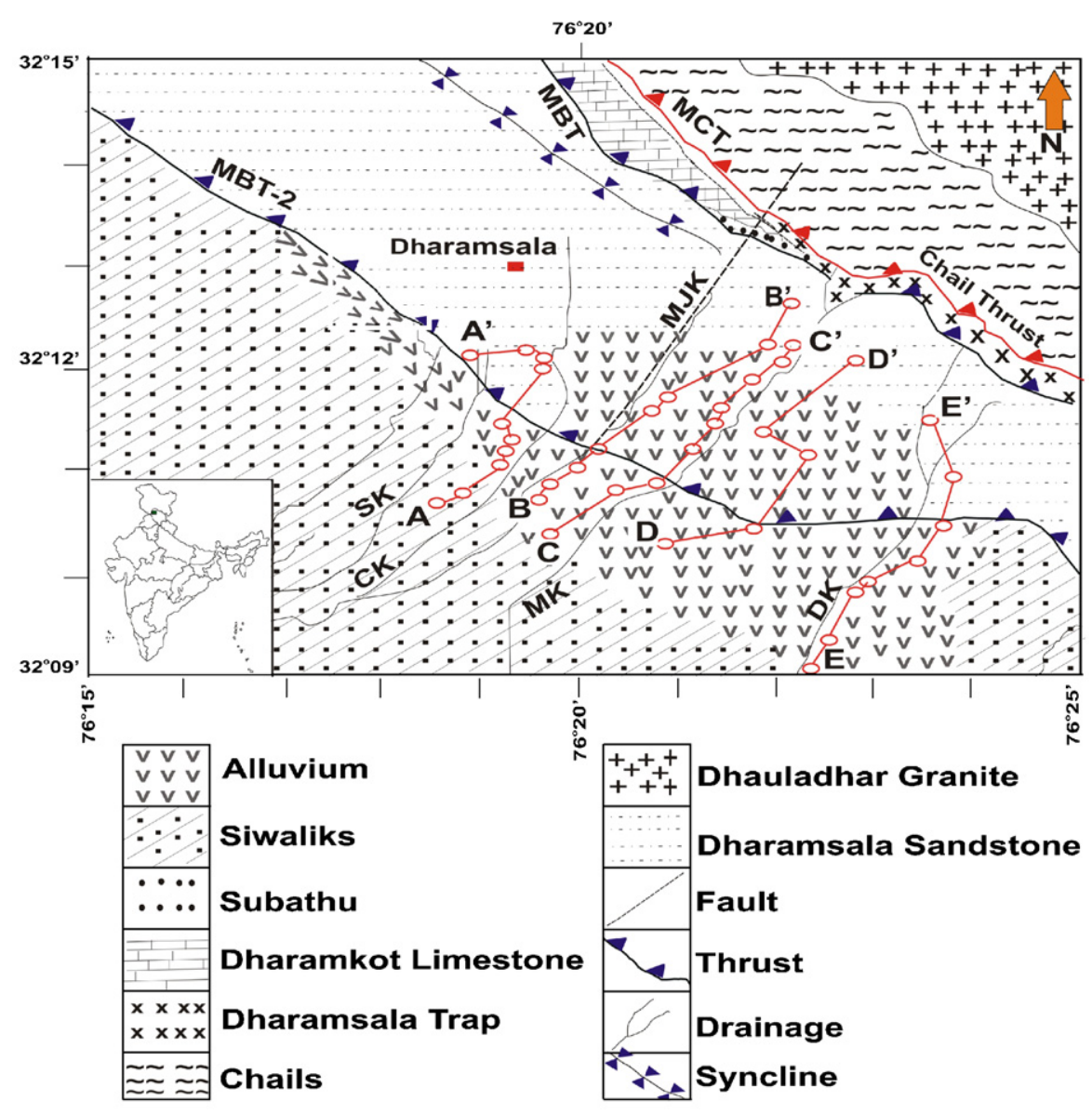

Fig. 1. Geological and tectonic map of the area under study along with sampling profiles (namely, $\mathrm{AA}^{\prime}, \mathrm{BB}^{\prime}, \mathrm{CC}^{\prime}, \mathrm{DD}^{\prime}$ and $\mathrm{EE}^{\prime}$ ), whereas sampling points are marked by hollow circles, tectonic features $(\mathrm{MBT}=$ Main Boundary Thrust, MCT $=$ Main Central Thrust) and drainage systems $(\mathrm{SK}=\mathrm{Sarah}$ Khad, CK = Churan Khad, MJK = Manjhi Khad, MK = Manuni Khad, DK = Darun Khad) (modified after Mahajan et al., 1997).

Dharamsala area of the NW Himalayas lies on the southern slope of the Dhauladhar range. The area is seismically active. Diverse lithology within a short span of distance makes the study area tectonically significant and shows the features of ductile shear zone due to the presence of distinct thrust planes. From south to north these are MBT-2 (locally known as Drini Thrust), MBT and MCT (or Chail Thrust) (Fig. 1). Diverse lithology (Mahajan et al., 1997) within a short span of distance makes the study area significant both tectonically and environmentally. The individual formations and groups are separated from one another by longitudinal thrust systems (Mahajan and Virdi, 2000) (Fig. 1) and the area is cross-cut by transverse faults/lineaments trending northeast-southwest. Kumar and Mahajan (2001) have correlated the Kangra earthquake (1905) and the Dharamsala earthquake (1986) with MBT and its subsidiary Drini thrust in the north-east to south-west direction while the Dharamsala earthquake (1978) is correlated with a transverse fault.

\subsection{Sampling procedure}

To carry out the investigations in the soil gas, transverse profile surveys were conducted across the probable fault locations of MBT-2. During these surveys soil-gas samples were col- lected along the traverses crossing the observed structures and were analyzed for radon and helium. Soil-gas samples were collected in sample bags at a depth of about $0.7-1.0 \mathrm{~m}$ by using a hollow steel probe method described elsewhere (Walia et al., 2005a; Fu et al., 2005).

\section{Results and discussions}

The results of soil-gas concentration variations of radon and helium distribution along the five profiles are shown in Fig. 2. During the investigation 40 samples were collected for helium (using 1 litre bags) and radon (using 3 litre bags) analyses, covering an area of $40 \mathrm{~km}^{2}$ along all the five profies.

In order to identify possible threshold values of anomalous soil helium and radon concentrations, various statistical methods have been used by different authors in the past (Guerra and Lombardi, 2001; Fu et al., 2005; Walia et al., 2005a). In our context due to weak deep gas leaks, helium anomalies are defined as the concentration on or above $5.30 \mathrm{ppm}$, because there is no potential source to generate additional helium relative to air near the ground process. In the case of radon concentration, statistical threshold value of gas anomalies is fixed at mean plus one standard deviation $(1 \sigma)$ for each profile and anomalously high and low values were neglected, which may 

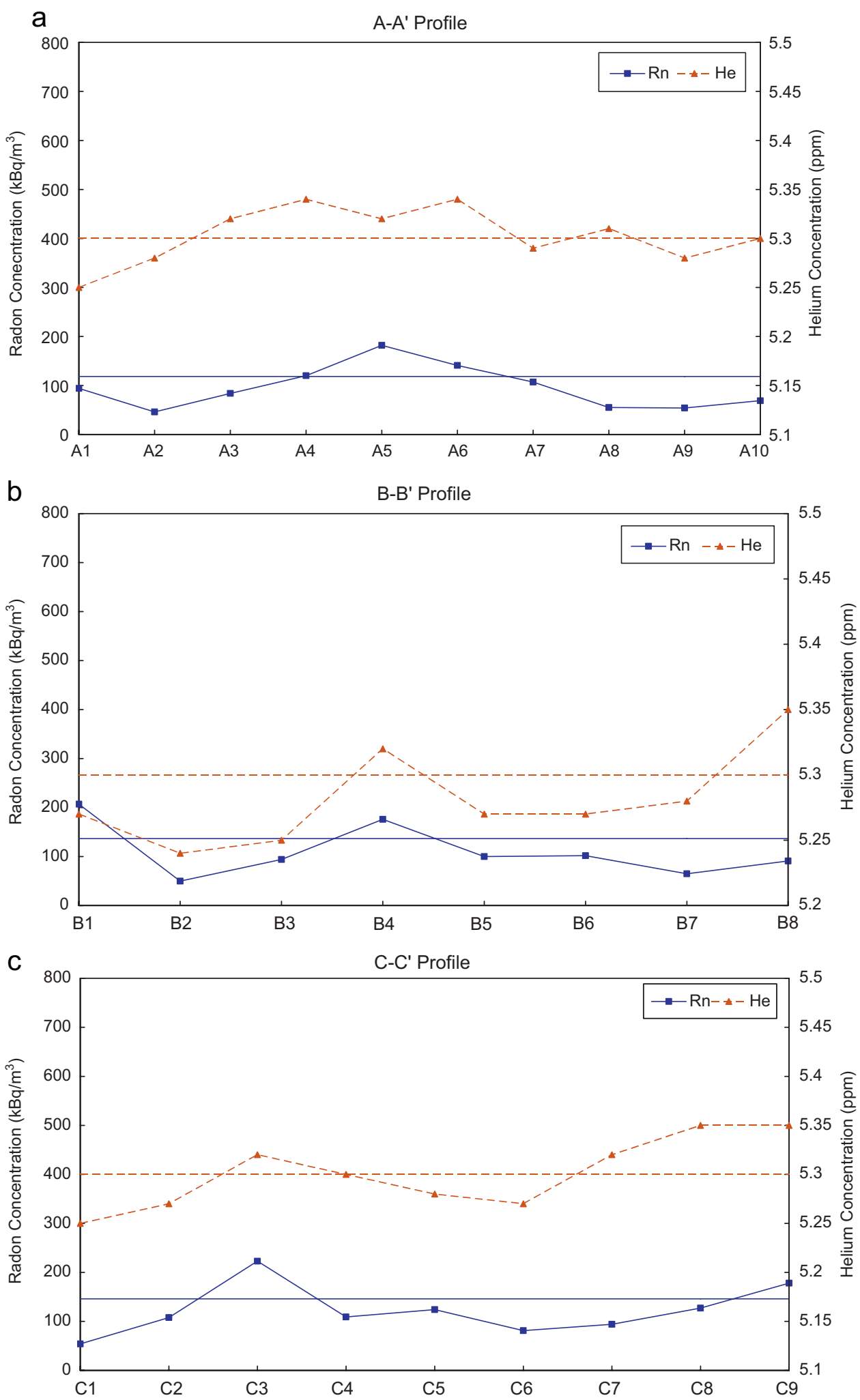

Fig. 2. Variations of radon and helium soil-gas concentrations along each profile viz., (a) A-A' (b) B-B' (c) C-C' (d) D-D' (e) E-E', where the horizontal lines represent the threshold value (i.e. Average +1 Standard deviation for radon and $5.3 \mathrm{ppm}$ for helium) used to identify the anomalies.

cause unnecessary high deviation and perturb the real anomalies. The soil radon anomalies cannot be fixed absolutely for whole data set as radon emanation is effected by many other parameters. The threshold values are marked by dotted and solid lines in each graph for helium and radon, respectively (Fig. 2). 

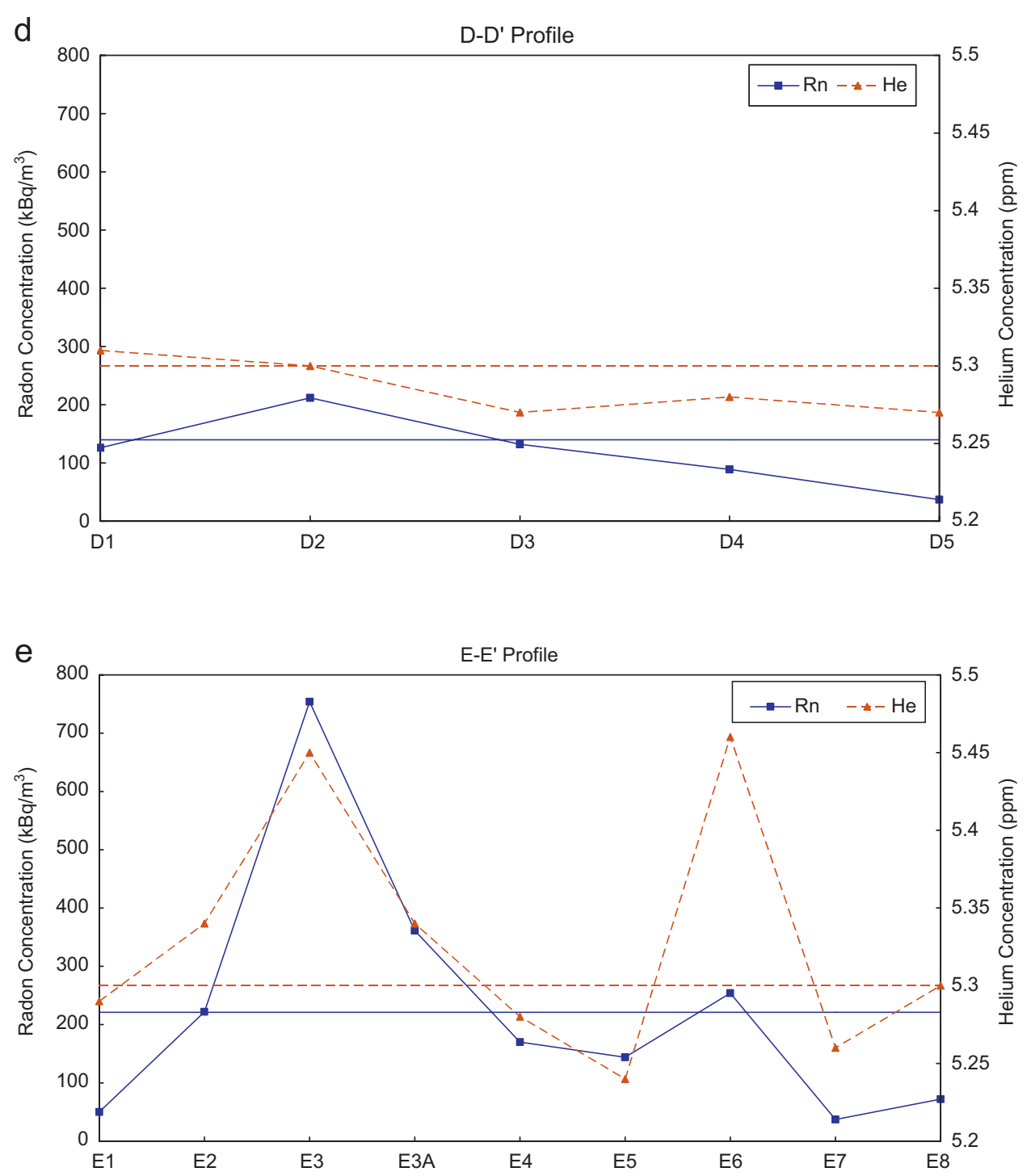

Fig. 2. (continued).

The sampling points are almost equally distributed on both north and south sides of MBT-2 as shown in Fig. 1. The spatial distributions of helium and radon gases along each profile are shown in Fig. 3. The sample locations are marked in ascending order along the profiles from south to north (Fig. 1), e.g. $\mathrm{A}-\mathrm{A}^{\prime}$ profile starts from point $\mathrm{A}$ (numbered $\mathrm{A} 1$ ) and finishes at point $\mathrm{A}^{\prime}$ (numbered $\mathrm{A} 10$ ). Helium concentration varies from 5.24 to $5.46 \mathrm{ppm}$ and radon concentration shows a variation from 37 to $754 \mathrm{kBq} / \mathrm{m}^{3}$. The highest values of both helium and radon were recorded at point E3 (Fig. 2e). These high values of radon and helium at point E3 are reconfirmed by re-sampling and also by sampling at few meters away from point E3A (Fig. 2e). Soil-gas flux is found to be low in Siwaliks/sandstone as compared with alluvium. The average radon concentration in Siwaliks/sandstone is found to be $60 \mathrm{kBq} / \mathrm{m}^{3}$ with a standard deviation of $18 \mathrm{kBq} / \mathrm{m}^{3}$, whereas the average radon concentration in alluvium is many folds higher. Point $\mathrm{C} 1$ shows the lowest value of radon, i.e. $37 \mathrm{kBq} / \mathrm{m}^{3}$ (Fig. 2c), and has the helium concentration of $5.24 \mathrm{ppm}$ equal to the air concentration of helium. The low values in sandstone/Siwaliks shows that the basement is more compact and has low porosity as compared with alluvium which hinder the radon migration. Due to this fact, almost no radon anomaly was recorded in sandstone/Siwaliks, but helium does show some anomalies (Figs. 3a and $b$ ). Good example of this pattern is clearly observed at point A10 (Fig. 2a) where helium anomaly is observed (Figs. 2a and $3 \mathrm{~A}$ ), but radon concentration shows no anomalous value (Figs. 2a and 3A) although this point is almost located on MBT-2. This clearly indicates that radon variation is not only effected by the tectonic structures but also by the change in lithology.

Spatial distribution of helium and radon data points along the profiles across the MBT-2 shows that helium has more number of anomalies (i.e. 18) (Fig. 3A) as compared with radon (i.e. 11) (Fig. 3B). Coexisted spatial distribution of helium and radon (Fig. 3C) shows better results than individual gas species used for this study. In all the three cases (i.e. for individual radon, 

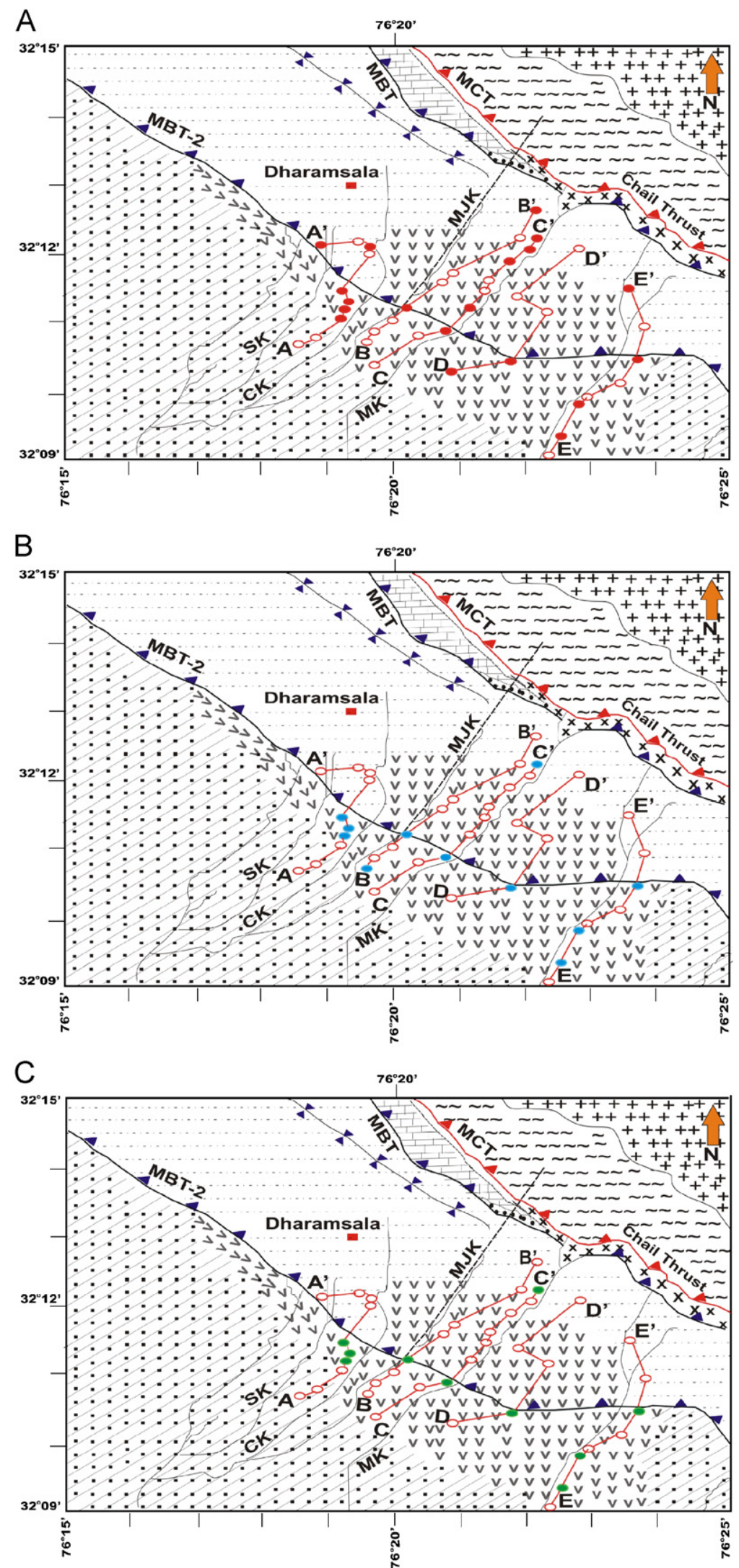

Fig. 3. Spatial distribution of soil-gas data points and anomalies (solid circles): (A) Helium (in red) (B) Radon (in blue) and (C) Coexisted anomalies in both helium and radon (in green). 
helium and coexisted anomalies) anomalous values are observed along the location of MBT-2 (Fig. 3). Anomalies are not only recorded along MBT-2 but also along Churan Khad (CK), Manuni Khad (MK) and Darun Khad (DK). These anomalies indicate the presence of lineaments along this drainage system (Figs. 1 and 3). A similar kind of intersection pattern of longitudinal thrust and transverse lineaments is observed along Manji Khad (MJK) (Fig. 1) and in the adjoining area of Dharamsala (Dhar et al., 2002).

\section{Conclusions}

Soil helium and radon gas patterns, combined with morphological and geological observations, can supply useful constraints for deformation tectonic environments. The present study concludes that radon concentration not only varies with tectonic features but also with the change in lithology. From the radon and helium anomalies it was observed that the anomalies are not only distributed on the conspicuous thrust MBT-2 but also along the drainage system in the study area. Anomalies along these drainage systems indicate the presence of transverse lineaments which are intersecting the longitudinal thrust (MBT-2). Intersection of these two fault systems might have made the region tectonically active and interesting for the further studies.

\section{Acknowledgments}

Authors VW/TFY and SM/AK/SS/BSB/SD are grateful to the National Science Council of Taiwan and the Department of Science \& Technology of India for providing the financial support under the projects (NSC 94-2119-M-492-001 \& DST/23(476)/SU/2004), respectively. Two anonymous reviewer's critical comments and suggestions have helped to improve the paper.

\section{References}

Chyi, L.L., Quick, T.J., Yang, T.F., Chen, C-H., 2005. Soil gas radon spectra and earthquakes. Terr. Atmos. Ocean. Sci. 16, 763-774.

Ciotoli, G., Guerra, M., Lombardi, E., Vittori, E., 1998. Soil gas survey for tracing seismogenic faults: a case study in the Fucino basin, Central Italy. J. Geophys. Res. 103, 23781-23794.
Dhar, S., Singh, S., Dogra, M., Kochhar, N., 2002. Geological significance of radon in eco-system of Dharamsala area, Himachal Pradesh, India. Natural Hazards and their Mitigations. Special Bulletin of IGA, PU, Chandigarh, vol. 35(2), pp. 139-147.

Fu, C.C., Yang, T.F., Walia, V., Cheng, C.-H., 2005. Reconnaissance of soil gas composition over the buried fault and fracture zone in southern Taiwan. Geochem. J. 39, 427-439.

Fu, C.C., Yang, T.F., Du, J., Walia, V., Chen, Y.G., Liu, T.K., Chen, CH., 2008. Variations of helium and radon concentrations in soil gases from an active fault zone in southern Taiwan. Radiat. Meas., this issue, doi:10.1016/j.radmeas.2008.03.025.

Font, L1., Baixeras, Moreno, V., Bach, J., 2007. Soil radon levels across the Amer fault. Radiat. Meas., this issue, doi:10.1016/j.radmeas.2008.04.072.

Gansser, A., 1964. Geology of Himalayas. Interscience, New York.

Guerra, M., Lombardi, S., 2001. Soil-gas method for tracing neotectonic faults in clay basins: the Pisticci field (Southern Italy). Tectonophysics 339, 511-522.

Kumar, S., Mahajan, A.K., 2001. Seismotectonics of the Kangra region North Himalaya. Tectonophysics 331 (4), 359-371.

Mahajan, A.K., Virdi, N.S., 2000. Preparation of Landslides Hazard Zonation Map of Dharamsala Town \& adjoining areas, District Kangra (H.P.). Project report, H.P. Government, 45p.

Mahajan, A.K., Kumar, S., Chabak, S.K., 1997. Local gravity anomaly and geotectonics in the Dharamsala and Palampur area, North West Himalayas. J. Geol. Soc. Ind. 50, 75-84.

Toutain, J.-P., Baubron, J.C., 1999. Gas geochemistry and seismotectonics: a review. Tectonophysics 304, 1-27.

Walia, V., Su, T.C., Fu, C.C., Yang, T.F., 2005a. Spatial variations of radon and helium concentration in soil gas across Shan-Chiao fault, Northern Taiwan. Radiat. Meas. 40, 513-516.

Walia, V., Virk, H.S., Yang, T.F., Mahajan, S., Walia, M., Bajwa, B.S., 2005b. Earthquake prediction studies using radon as a precursor in N-W Himalayas India: a case study. Terr. Atmos. Ocean. Sci. 16 (4), 775-804.

Walia, V., Virk, H.S., Bajwa, B.S., 2006. Radon precursory signals for some earthquakes of magnitude $>5$ occurred in N-W Himalaya. Pure Appl. Geophys. 163, 711-721.

Yang, T.F., Chou, C.Y., Chen, C-H., Chyi, L.L., Jiang, J.H., 2003. Exhalation of radon and its carrier gases in SW Taiwan. Radiat. Meas. 36, 425-429.

Yang, T.F., Walia, V., Chyi, L.L., Fu, C.C., Wang, C.C., Chen, C-H., Liu, T.K., Song, S.R., Lee, C.Y., Lee, M., 2005. Variations of soil radon and thoron concentrations in a fault zone and prospective earthquakes in SW Taiwan. Radiat. Meas. 40, 496-502.

Yang, T.F., Fu, C.C., Walia, V., Chen, C.-H., Chyi, L.L., Liu, T.K., Song, S.R., Lee, M., Lin, C.W., Lin, C.C., 2006. Seismo-geochemical variations in SW Taiwan: multi-parameter automatic gas monitoring results. Pure Appl. Geophys. 163, 693-700. 